\section{(6) OPEN ACCESS}

\title{
Efficacy of oral vancomycin in recurrent primary sclerosing cholangitis following liver transplantation
}

\author{
Penelope Hey, ${ }^{1}$ Julie Lokan, ${ }^{2}$ Paul Johnson, ${ }^{3}$ Paul Gow ${ }^{1}$
}

\begin{abstract}
'Department of
Gastroenterology, Austin Health, Heidelberg, Victoria, Australia ${ }^{2}$ Department of Pathology, Austin Health, Heidelberg, Victoria, Australia ${ }^{3}$ Department of Infectious Diseases, Austin Health, Heidelberg, Victoria, Australia
\end{abstract}

\section{Correspondence to Dr Penelope Hey, penelope.hey@austin.org.au}

Accepted 8 August 2017

\section{CrossMark}

To cite: Hey P, Lokan J, Johnson P, et al. BMJ Case Rep Published Online First: [please include Day Month Year]. doi:10.1136/bcr-2017221165

\section{SUMMARY}

Primary sclerosing cholangitis (PSC) is a liver disease that leads to progressive destruction and stricturing of the biliary tree. Unfortunately, apart from orthotopic liver transplantation (OLT), there are no universally accepted therapies to treat this disease. Even following transplantation, recurrence of PSC is seen in approximately one quarter of patients and leads to high rates of graft failure. Oral vancomycin, through possible immunomodulatory and anti-inflammatory mechanisms, has been shown in small-scale studies to be successful in improving liver function tests in patients with pretransplant PSC. We report the first case of an adult patient diagnosed with recurrent PSC 4 years after OLT who was treated with oral vancomycin leading to complete normalisation of his liver biochemistry. This case adds to the growing literature of a potential therapeutic role for this antibiotic in PSC and highlights interesting questions regarding mechanisms of disease.

\section{BACKGROUND}

Primary sclerosing cholangitis (PSC) is a chronic cholestatic liver disease of unknown aetiology. It is characterised by progressive fibrosis and destruction of the intra and/or extrahepatic biliary tree. In the majority of patients, the disease is progressive with a median life expectancy of one to two decades without orthotopic liver transplantation (OLT). ${ }^{1}$ Currently, there is no medical treatment that has been shown to alter the natural history of the disease. While liver transplantation is the only treatment option for patients with advanced biliary cirrhosis and portal hypertension, it is estimated that PSC will recur in one quarter of patients who undergo transplantation. ${ }^{1}$ Recurrence of PSC after OLT is associated with high rates of retransplantation and reduced graft and patient survival. ${ }^{2}$ There is no established medical therapy for the treatment of recurrent PSC after transplantation. This report is the first to describe the successful treatment of recurrent PSC post-transplantation with vancomycin in an adult patient.

\section{CASE PRESENTATION}

A 33-year-old man underwent liver transplantation in 2010 for end-stage liver disease secondary to PSC. The patient has a history of ulcerative colitis. Two years after liver transplantation, the patient developed toxic megacolon requiring a subtotal colectomy and ileostomy. He underwent J-pouch formation and stoma reversal in 2013 with several episodes of pouchitis treated with long-term ciprofloxacin $500 \mathrm{mg}$ daily.

The patient was diagnosed with PSC at the age of 14 years old. He was referred for transplantation in May 2010 with refractory ascites, jaundice, sarcopenia and a Model of End-Stage Liver Disease score of 17. At transplant work-up, he had an alkaline phosphatase (ALP) of 396 units/L (normal 40-140), bilirubin of $83 \mu \mathrm{mol} / \mathrm{L}$ (normal $<21 \mu \mathrm{mol} / \mathrm{L}$ ) and an international normalised ratio of 1.5 . He had a negative antinuclear antibody (ANA), an IgG level of $21.9 \mathrm{~g} / \mathrm{L}$ (normal 7.0-16.5) and a C-reactive protein of $11.1 \mathrm{~g} / \mathrm{L}$ (normal <8.0).

$\mathrm{He}$ underwent transplantation in October 2010 and made an unremarkable post-transplant recovery. His weight and sarcopenia improved following liver transplantation to a stable weight of $73 \mathrm{~kg}$ and body mass index of 22 . Post-transplant medications included weaning oral prednisolone, azathioprine $150 \mathrm{mg}$ daily and cyclosporine $400 \mathrm{mg}$ twice daily. For the first 2 years after transplantation, liver biochemistry remained within normal range with no transplant-related complications.

Two years after transplantation, the patient developed acutely deranged liver function tests (LFTs). His ALP peaked at 703 units/L, gamma-glutamyltransferase (GGT) at 309 units/L (normal <60) and alanine aminotransferase (ALT) at 125 units/L (normal <41). A diagnosis of acute cellular rejection was confirmed on liver histology. A MR cholangiopancreatography (MRCP) at this time was normal, with no evidence of biliary pathology. Following treatment of acute rejection with pulsed intravenous methylprednisolone and an increase in his cyclosporine dosage, his LFTs again normalised with an ALP level of 134 units/L, GGT level of 95 units/L and ALT of 44 units/L. This biochemical improvement remained stable for 2 years.

However, 4 years following transplantation, the patient developed recurrent and progressive derangement of his liver biochemistry (figure 1). He developed mild pruritus and increased fatigue.

\section{INVESTIGATIONS}

His ALP increased to 430 units/L, ALT 269 units/L and GGT 452 units/L. An MRCP at this stage demonstrated new stricturing of the intrahepatic biliary tree, particularly involving the left lobe of the liver. A liver biopsy showed periductal oedema, lymphoplasmacytic infiltration and acute cholangitis (figure 2). 


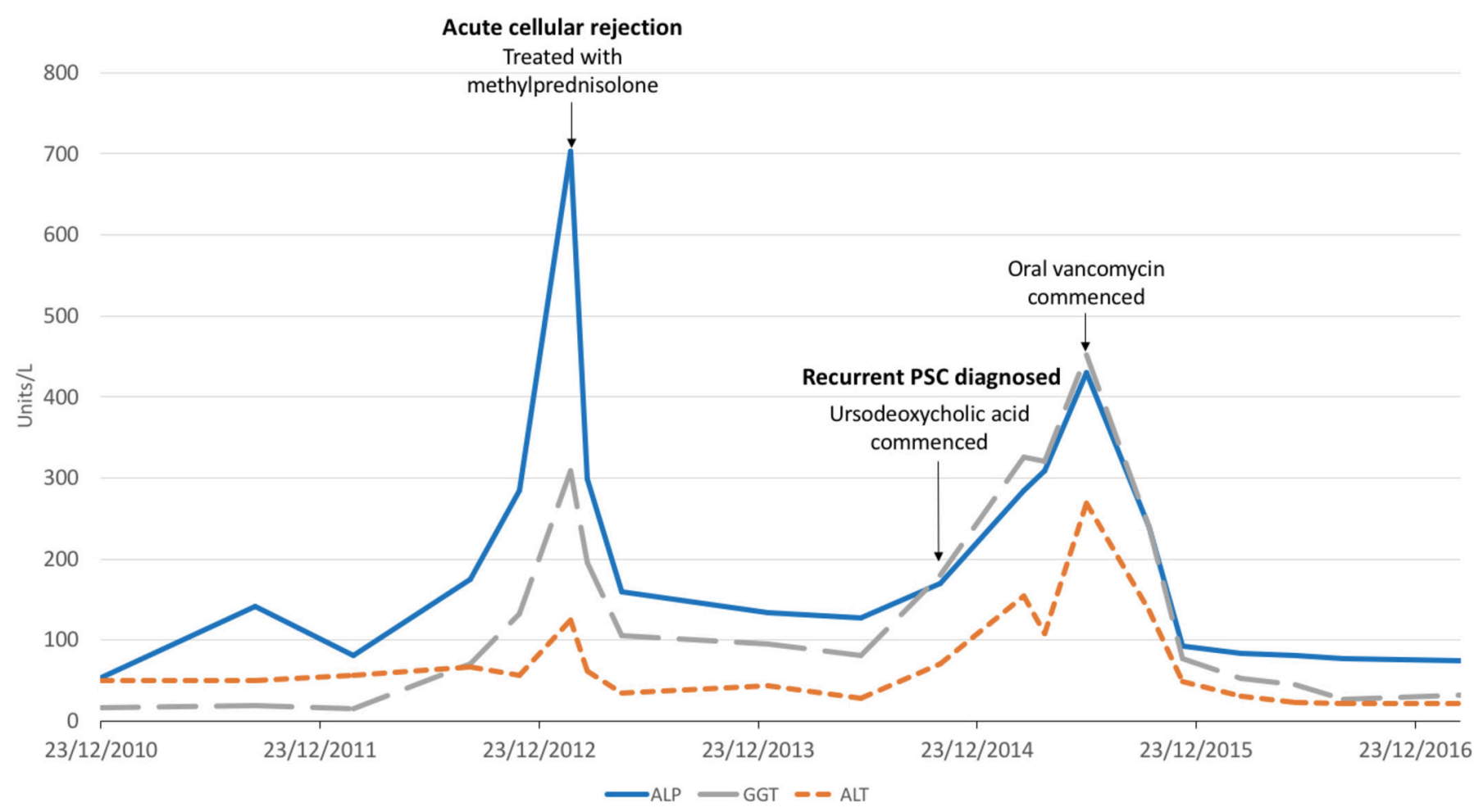

Figure 1 Liver biochemistry following liver transplantation: an episode of histologically confirmed acute cellular rejection in 2012 was treated with intravenous methylprednisolone dosed at $500 \mathrm{mg}$ for 3 days and a prednisolone weaning regimen thereafter. A diagnosis of recurrent PSC was made in 2014 based on imaging and histology findings. Ursodeoxycholic acid was dosed at $750 \mathrm{mg}$ twice daily and vancomycin at $250 \mathrm{mg}$ twice daily. ALP, alkaline phosphatase; ALT, alanine aminotransferase; GGT, gamma-glutamyltransferase; PSC, primary sclerosing cholangitis.

\section{DIFFERENTIAL DIAGNOSIS}

Alternative causes for this patient's deranged LFTs include chronic rejection and biliary stricturing secondary to ischaemia, cholangitis or narrowing at the anastomotic site. Liver histology was not consistent with rejection and the development of stricturing years after transplantation in the absence of ischaemic or infective insults excluded these as a diagnosis. With typical MRCP, biochemical and histology findings, a diagnosis of recurrent PSC was made.

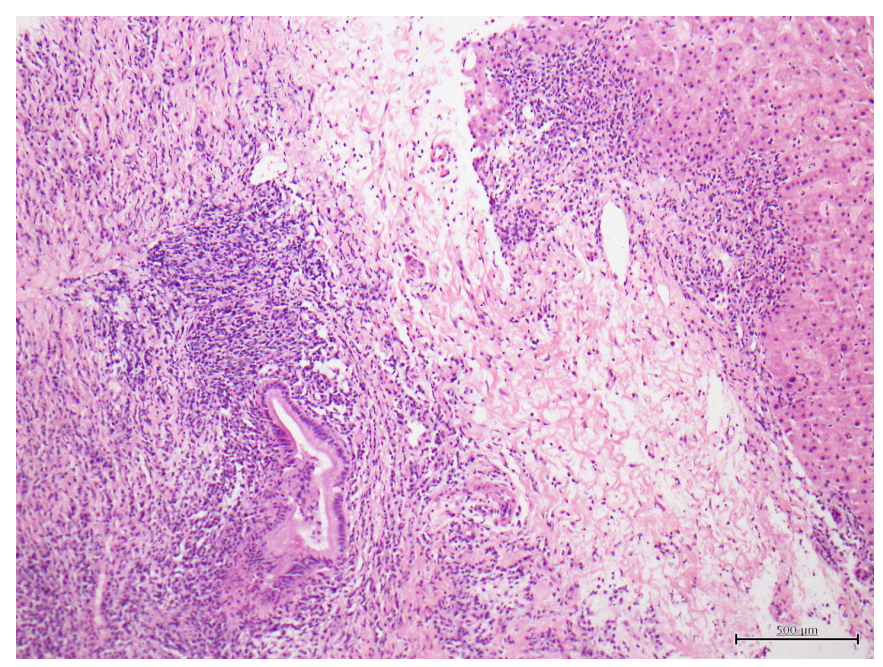

Figure 2 Liver biopsy demonstrating periductal oedema, lymphoplasmacytic infiltration and acute cholangitis consistent with recurrent primary sclerosing cholangitis.

\section{TREATMENT}

The patient was commenced on ursodeoxycholic acid at $15 \mathrm{mg} /$ $\mathrm{kg}$ /day in two divided doses of $500 \mathrm{mg}$. This was increased to $750 \mathrm{mg}$ twice daily with no significant improvement in his liver biochemistry. With progressively deranged LFTs, he was prescribed a therapeutic trial of oral vancomycin $250 \mathrm{mg}$ twice daily in June 2015. His LFTs completely normalised within 2 months of commencement. Despite gradual reductions to his immunosuppression over time since his transplantation, no changes were made around the time of vancomycin commencement and he continues on azathioprine $100 \mathrm{mg}$ daily, prednisolone $2.5 \mathrm{mg}$ daily and cyclosporine $125 \mathrm{mg}$ twice daily. Other medication at last follow-up includes ursodeoxycholic acid $750 \mathrm{mg}$ twice daily, ciprofloxacin $500 \mathrm{mg}$ daily for prophylaxis against pouchitis, cholecalciferol $25 \mathrm{mcg}$ daily and calcium carbonate $600 \mathrm{mg}$ daily.

\section{OUTCOME AND FOLLOW-UP}

In the 22 months since commencing vancomycin, his LFTs still remain within the normal range. Interestingly, despite normal LFTs, a repeat MRCP demonstrates stable, but persistent, intrahepatic duct stricturing and beading. The patient reports a possible reduction in pruritus following commencement of vancomycin. He has not experienced any adverse effects attributable to oral vancomycin and continues on a dose of $250 \mathrm{mg}$ twice daily.

\section{DISCUSSION}

There is currently no accepted medical therapy for PSC that recurs after liver transplantation. In the majority of patients who develop recurrent PSC, the disease is progressive and associated 
with reduced graft function, high rates of retransplantation and decreased survival. ${ }^{2}$ This case is the first to report the efficacy of vancomycin in treating post-transplant PSC in an adult and adds to the growing literature suggesting oral vancomycin may play a significant role in treating PSC in all populations.

The pathogenesis of PSC is thought to be a combination of idiopathic, genetic and immune-mediated diseases with an association between enteric dysbiosis and the microbiome. One theory is that enterohepatic circulation of microbial pathogens promotes biliary inflammation and stricturing. ${ }^{3}$ As such, various antibiotics, through their effect on gut bacteria, have been proposed as potential treatment strategies for PSC. Tetracycline, metronidazole and azithromycin have all been studied with generally positive results. Oral vancomycin can be further added to this list, with several pilot studies and case series showing normalisation of biochemistry and improved liver histology following use of this antibiotic in patients with pretransplant PSC. $^{45}$

Oral vancomycin is a glycopeptide antibiotic with Gram-positive activity, which is largely non-absorbed from the gastrointestinal tract. ${ }^{4}$ Therefore, its demonstrated efficacy in PSC has significant implications with respect to understanding disease aetiology. As it is not absorbed after oral administration, its effect must be directly on bacterial populations within the gut, rather than in the enterohepatic circulation or biliary system. The hepatic biochemical benefits seen with vancomycin in PSC therefore suggest that liver disease and biliary damage in this condition may be due to hepatotoxic chemicals or bacterial-derived products released into the portal circulation from a pathogenic enteric bacterial population.

The other important observation from our case is that vancomycin resulted in complete normalisation of liver biochemistry but no change in biliary anatomy. On repeat MRCP with normal LFTs, our patient had persistent, but stable, intrahepatic biliary stricturing following treatment. This suggests that biochemical dysfunction seen in PSC is not primarily due to disordered bile flow resulting from a strictured biliary system. Instead, LFT derangement may be more a result of hepatic inflammation, independent of biliary anatomy as quantified on MRCP. This suggests that the possible therapeutic action of vancomycin is in reversing inflammation. Further supporting this theory is a study investigating $\mathrm{T}$ cell responses in a paediatric population with inflammatory bowel disease and PSC. It showed that administration of oral vancomycin promoted a regulatory $\mathrm{T}$ cell response with anti-inflammatory properties. ${ }^{6}$

Only one case in the literature has reported the successful use of vancomycin in the treatment of recurrent PSC postliver transplantation. This was in a paediatric patient who developed recurrent disease within 6 months of OLT. Similar to our case, this patient showed normalisation of her LFTs after commencement of oral vancomycin and a return to normal liver structure and anatomy on histology and imaging. Paediatric PSC can also behave differently to adults, with higher rates of autoimmune hepatitis overlap. Unlike our case, the paediatric patient reported did have elevated ANA level and inflammatory markers. Interestingly, these normalised with vancomycin treatment. This serves to further highlight the potential immunomodulatory role of vancomycin in this population. ${ }^{7}$

In conclusion, there is an unmet need for medical therapies to treat post-transplant PSC given the significant implications it has on graft and patient survival. This case offers one such promising therapy, demonstrating complete biochemical response in a patient with recurrent PSC following a trial of oral vancomycin. Furthermore, the lack of enteric absorption of vancomycin provides support for a direct effect of the intestinal microbiome in the pathogenesis of PSC. Ultimately, more studies are needed to assess the efficacy and safety of this antibiotic in patients with recurrent disease following OLT.

\section{Learning points}

- Recurrent primary sclerosing cholangitis (PSC) followingliver transplantation leads to reduced graft and patient survival. There are currently no known established medical therapies to delay progression of the disease.

- Oral vancomycin has shown promising results by improving liver biochemistry in patients with pre-transplant PSC, and, pending further studies, may offer a potential therapy for recurrent PSC following liver transplantation.

- The effects of oral vancomycin may be twofold. Being largely non-absorbable, it likely has direct effects on the enteric microbiome as well as possible anti-inflammatory properties.

- More research is required to further elucidate the efficacy and safety of oral vancomycin in recurrent PSC.

Contributors PH reviewed the details of the case, created figures and drafted the case report. All authors contributed to the editing of the final product. JL reviewed and prepared histopathology slides and edited the article prior to submission. PG and PJ have been involved in the long-term management of this patient. They also contributed significantly to the writing and editing of this report.

Competing interests None declared.

Patient consent Obtained.

Provenance and peer review Not commissioned; externally peer reviewed.

Open Access This is an Open Access article distributed in accordance with the Creative Commons Attribution Non Commercial (CC BY-NC 4.0) license, which permits others to distribute, remix, adapt, build upon this work non-commercially, and license their derivative works on different terms, provided the original work is properly cited and the use is non-commercial. See: http://creativecommons.org/ licenses/by-nc/4.0/

(c) BMJ Publishing Group Ltd (unless otherwise stated in the text of the article) 2017. All rights reserved. No commercial use is permitted unless otherwise expressly granted.

\section{REFERENCES}

1 Chapman R, Fevery J, Kalloo A, et al. American association for the study of liver diseases. Diagnosis and management of primary sclerosing cholangitis. Hepatology 2010:51:660-78.

2 Cholongitas E, Shusang V, Papatheodoridis GV, et al. Risk factors for recurrence of primary sclerosing cholangitis after liver transplantation. Liver Transp/ 2008;14:138-43.

3 Ravikumar R, Tsochatzis E, Jose S, et al. Risk factors for recurrent primary sclerosing cholangitis after liver transplantation. J Hepatol 2015;63:1139-46.

4 Tabibian JH, Weeding E, Jorgensen RA, et al. Randomised clinical trial: vancomycin or metronidazole in patients with primary sclerosing cholangitis - a pilot study. Aliment Pharmacol Ther 2013;37:604-12.

5 Rahimpour S, Nasiri-Toosi M, Khalili E-DN, et al. A triple blinded, randomized, placebocontrolled clinical trail to evaluate the efficacy and safety of oral vancomycin in primary sclerosing cholangitis: A pilot study. J Gastrointest Liver Dis 2016;25:457-64.

6 Abarbanel DN, Seki SM, Davies Y, et al. Immunomodulatory effect of vancomycin on Treg in pediatric inflammatory bowel disease and primary sclerosing cholangitis. J Clin Immunol 2013:33:397-406.

7 Davies YK, Tsay CJ, Caccamo DV, et al. Successful treatment of recurrent primary sclerosing cholangitis after orthotopic liver transplantation with oral vancomycin. Case Rep Transplant 2013;2013:1-5. 
Copyright 2017 BMJ Publishing Group. All rights reserved. For permission to reuse any of this content visit http://group.bmj.com/group/rights-licensing/permissions.

BMJ Case Report Fellows may re-use this article for personal use and teaching without any further permission.

Become a Fellow of BMJ Case Reports today and you can:

- Submit as many cases as you like

- Enjoy fast sympathetic peer review and rapid publication of accepted articles

Access all the published articles

- Re-use any of the published material for personal use and teaching without further permission

For information on Institutional Fellowships contact consortiasales@bmjgroup.com

Visit casereports.bmj.com for more articles like this and to become a Fellow 